\title{
One-pot gold-catalyzed synthesis of 3-silylethynyl indoles from unprotected o-alkynylanilines
}

\author{
Jonathan P. Brand, Clara Chevalley and Jérôme Waser ${ }^{*}$
}

\section{Letter}

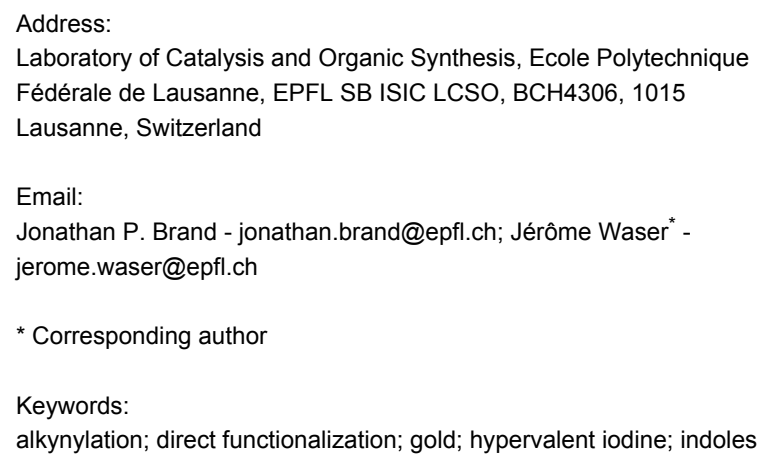

(C) 2011 Brand et al; licensee Beilstein-Institut. License and terms: see end of document.

\begin{abstract}
$\mathrm{The} \mathrm{Au}(\mathrm{III})$-catalyzed cyclization of 2-alkynylanilines was combined in a one-pot procedure with the $\mathrm{Au}(\mathrm{I})$-catalyzed $\mathrm{C} 3$-selective direct alkynylation of indoles using the benziodoxolone reagent TIPS-EBX to give a mild, easy and straightforward entry to 2-substituted-3-alkynylindoles. The reaction can be applied to unprotected anilines, was tolerant to functional groups and easy to carry out (RT, and requires neither an inert atmosphere nor special solvents).
\end{abstract}

\section{Introduction}

Indoles are widespread in both natural products and synthetic drugs $[1,2]$ and as a result, their synthesis and functionalization have been extensively studied [3,4]. Among the numerous syntheses of indoles, the cyclization of 2-alkynylanilines has the advantage that the resulting products, 2 -substituted indoles, are easily functionalized by electrophilic aromatic substitution at position 3. Traditionally, this transformation has been achieved in two separate steps, with isolation and purification of the 3-unsubstituted indole intermediate. Domino or one-pot processes constitute a more efficient access to organic molecules, as they avoid the use of time and resource consuming work-up, and purification procedures [5-7]. When considering the importance of multi-functionalized indoles, it is therefore not surprising that the aniline cyclization-electrophilic substitution sequence has been achieved by means of several metalcatalyzed domino processes (Scheme 1) [8-10].

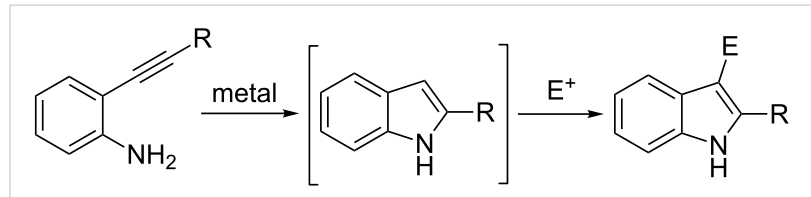

Scheme 1: Domino cyclization-substitution reactions of 2-alkynylanilines. 
Among the different $\pi$-activating metals capable of promoting nucleophilic attack on acetylenes, gold has recently attracted interest from the synthetic chemistry community [11-14]. Gold catalysts have also been used in domino sequences starting from $o$-alkynylanilines. Arcadi and Marinelli reported that goldcatalyzed cyclization of 2-alkynylanilines can be followed by 1,4 -addition to enones [15,16], iodination [17] or reaction with 1,3-dicarbonyl compounds [18]. Perumal recently demonstrated that aldehydes and nitroalkenes can be used as electrophilic partners $[19,20]$. Triple bonds can also serve as a second electrophile for the construction of tetrahydrofurans [21] and aryl-annulated $[a]$ carbazoles [22]. Nakamura examined the cyclization of $\mathrm{N}$-tosyl-o-alkynylanilines and observed an internal transfer of the sulfonyl group to the 3-position of the formed indoles $[23,24]$. Similar transformations were also achieved for the transfer of carbonyl groups, but using platinum catalysts [25-28].

To date, there are no gold- or platinum-catalyzed methods for the introduction of acetylenes as electrophiles. However, Cacchi developed a palladium-catalyzed domino sequence including cyclization of $o$-alkynyltrifluoroacetanilides and alkynylation with bromoacetylenes [29]. New methods are needed to expand the scope of this transformation and Au catalysis appears especially promising, due to its broad functional groups tolerance, which could allow the direct use of unprotected anilines.

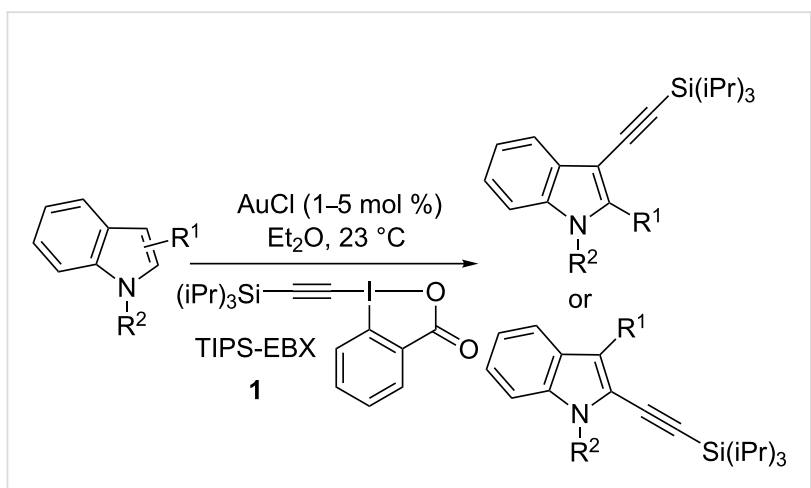

Scheme 2: Gold-catalyzed direct alkynylation of indoles with TIPSEBX (1).

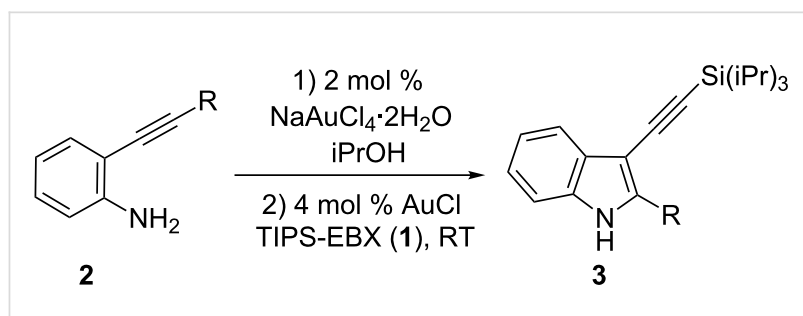

Scheme 3: One-pot alkynylaniline cyclization/direct alkynylation.
Recently, the direct alkynylation of preformed heterocycles has been intensively investigated [30-34]. Most of the developed methods involve the use of haloacetylenes. In contrast, our group has focused on the use of more reactive alkynyl hypervalent iodine reagents in order to expand the scope of direct alkynylation methods under milder conditions. We recently reported a mild procedure for the $\mathrm{C} 3$-selective alkynylation of indoles using $\mathrm{AuCl}$ and the commercially available benziodoxolone TIPS-EBX (1-[(triisopropylsilyl)ethynyl]-1,2-benziodoxol-3(1H)-one (1)) (Scheme 2) [35-40]. This methodology allowed the ethynylation of a wide range of indoles, including 2-substituted indoles.

In this letter we would like to report the one-pot combination of the cyclization of 2-alkynylanilines using $\mathrm{NaAuCl}_{4}$ as catalyst [15] followed by $\mathrm{C} 3$-alkynylation with $\mathrm{AuCl}$ and TIPS-EBX (1) (Scheme 3). This method offers an operationally simple access to 3-silylalkynyl indoles. To the best of our knowledge, this is the first example of a one-pot process combining a $\mathrm{Au}(\mathrm{III})$ and a $\mathrm{Au}(\mathrm{I})$ catalyst.

\section{Findings}

2-Alkynylanilines 2 can be efficiently prepared from 2-iodoanilines 4 and terminal alkynes via Sonogashira reaction with $\mathrm{Et}_{3} \mathrm{~N}$ as solvent (Scheme 4) [41,42]. The reaction was complete in less than $2 \mathrm{~h}$ and did not require aniline protection, solvent degassing or drying.

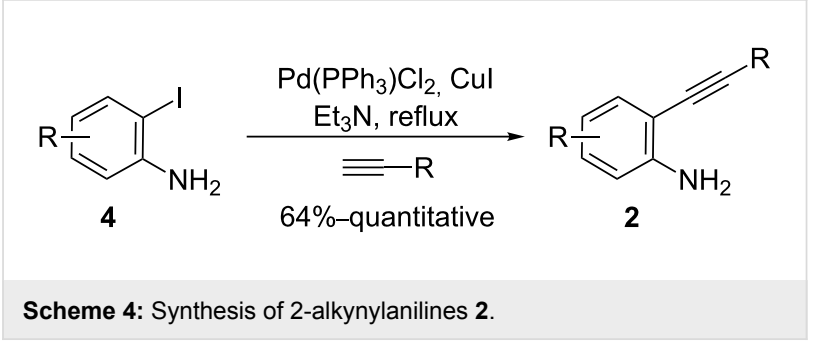

Our first investigations were focused on the cyclization of 2-(phenylethynyl)aniline (2a) into 2-phenylindole (5) with $\mathrm{AuCl}$ as the catalyst at room temperature (Scheme 5, step 1). Since $\mathrm{AuCl}$ has been shown to be the best catalyst for the alkynylation reaction [35], its use would allow a domino process with a single catalyst.

Despite the fact that the use of $\mathrm{AuCl}$ has been reported for step $1[19,20]$, in our hands the reaction was not reproducible at room temperature in a variety of solvents $\left(\mathrm{EtOH}, \mathrm{CH}_{3} \mathrm{CN}\right.$, $\mathrm{Et}_{2} \mathrm{O}$ ). A black precipitate was observed after catalyst addition, which we postulate was due to the stochastically degradation of $\mathrm{AuCl}$ under these conditions. $\mathrm{NaAuCl}_{4}$ has also been reported to be successful for the cyclization of 2-(phenylethynyl)aniline 


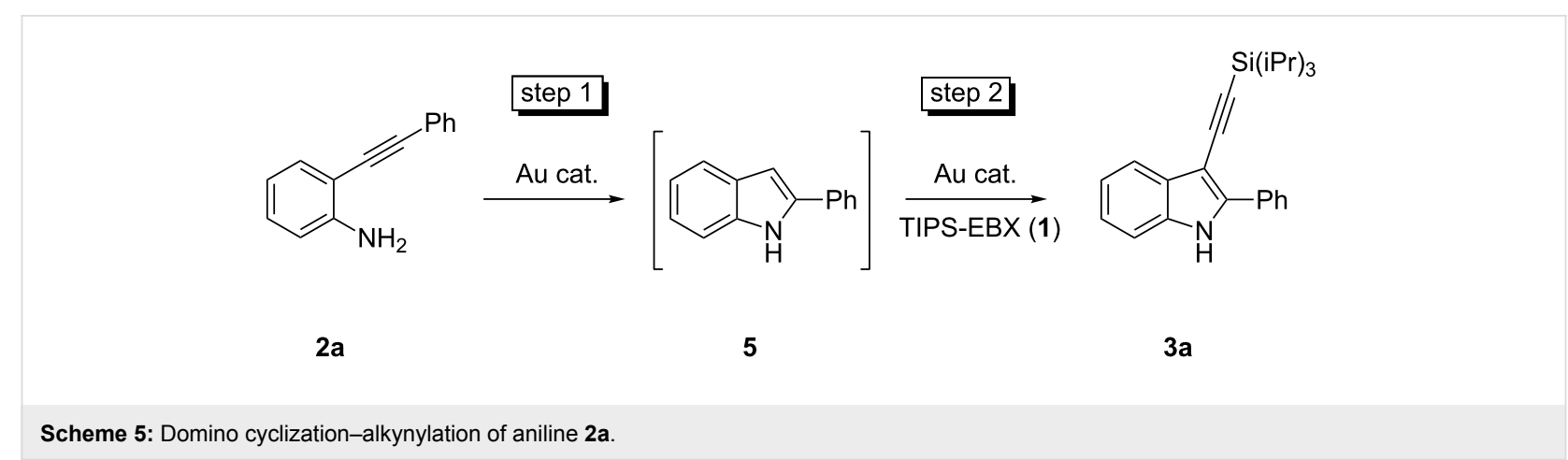

(2a) [15]. This catalyst was next examined in different solvents in order to maximize the chance of finding conditions suitable for both steps of the process. Aniline 2a was fully converted into 2-phenylindole (5) in $\mathrm{EtOH}, \mathrm{iPrOH}$ and $\mathrm{Et}_{2} \mathrm{O}$ after $3 \mathrm{~h}$ at room temperature using $2 \mathrm{~mol} \%$ of $\mathrm{NaAuCl}_{4}$ and there was no problem of reproducibility. Unfortunately, $\mathrm{NaAuCl}_{4}$ was not an efficient catalyst for the direct alkynylation of indole, as no reaction was observed when TIPS-EBX (1) was added to the reaction mixture.

We then investigated the successive addition of $\mathrm{NaAuCl}_{4}$ and $\mathrm{AuCl}$ in the same pot. Interestingly, one-pot sequential processes using both $\mathrm{Au}(\mathrm{I})$ and $\mathrm{Au}(\mathrm{III})$ have not yet been reported. $\mathrm{AuCl}$ and TIPS-EBX (1) were added when full conversion of the $\mathrm{NaAuCl}_{4}$-catalyzed cyclization was observed. When $2 \mathrm{~mol} \%$ of $\mathrm{NaAuCl}_{4}$ and $2 \mathrm{~mol} \% \mathrm{AuCl}$ were added, the second step was unsuccessful. However, with $2 \mathrm{~mol} \%$ of $\mathrm{NaAuCl}_{4}$ and $4 \mathrm{~mol} \%$ of $\mathrm{AuCl}$, full conversion was observed after $30 \mathrm{~h}$ at room temperature in $\mathrm{PrOH}$ (compared with $60 \%$ in $\mathrm{EtOH}$ and $40 \%$ in $\mathrm{Et}_{2} \mathrm{O}$ ). A basic work-up allowed the removal of the 2-iodobenzoic acid and column chromatography afforded the product in $96 \%$ yield (average of two reactions). Unfortunately, no reaction was observed when $\mathrm{AuCl}$ and TIPS-EBX (1) were added at the beginning of the reaction.

The scope of the reaction was then investigated (Scheme 6). Methyl- and fluoro groups were tolerated on the 2-aryl substituent to give products $\mathbf{3 b}$ and $\mathbf{3 c}$ in good yields. The low solubility of the indole intermediate in the synthesis of $\mathbf{3 d}$ led to a low yield for the direct alkynylation step. The addition of $\mathrm{CH}_{2} \mathrm{Cl}_{2}$ overcame this problem. Chloro substitution in paraposition of the aniline was also tolerated $(\mathbf{3 e}, \mathbf{3 f})$. Nevertheless, when the strongly electron-withdrawing cyano group was present, the cyclization step was too slow at room temperature. However, the use of $4 \mathrm{~mol} \%$ of $\mathrm{NaAuCl}_{4}$ and a reaction temperature of $80^{\circ} \mathrm{C}$ led to the formation of the desired indole, which could then be alkynylated at room temperature to give 3g. $o$-Hexynyl aniline (2h) was efficiently transformed into $\mathbf{3 h}$ in $85 \%$ yield. In order to access 2 -silyl indoles, the synthesis of the 2-trimethylsilylacetylene substituted compound $\mathbf{3 i}$ was attempted. Unfortunately, only traces of the indole intermediate were observed in this case. The reaction with 2-ethynylaniline

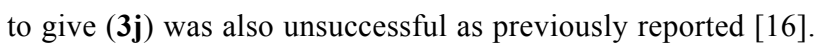

These first results on the direct alkynylation reaction combined in a one-pot procedure with gold-catalyzed indole ring formation are promising, and analogous strategies combining palladium-catalyzed synthesis of indoles [3] and gold-catalyzed alkynylation could also be envisaged. The next step will be to attempt a one-pot 3-steps synthesis of alkynyl indoles starting directly from iodoaniline.

In conclusion, an efficient access to 2-substituted 3-silylalkynyl indoles is reported. 2-Alkynylanilines underwent a sequential one-pot $\mathrm{Au}(\mathrm{III})$-catalyzed annulation and $\mathrm{Au}(\mathrm{I})$-mediated direct alkynylation. Importantly, this transformation did not require prior aniline protection and proceeded under mild conditions. This methodology represents the first example of the sequential addition of $\mathrm{Au}(\mathrm{III})$ and $\mathrm{Au}(\mathrm{I})$ catalysts for a one-pot process.

\section{Experimental}

\section{General procedure for the synthesis of 2-alkynylanilines 2}

A solution of 2-iodoaniline (4) (1 equiv), terminal alkyne (1.2-1.3 equiv), $\mathrm{PdCl}_{2}\left(\mathrm{PPh}_{3}\right)_{2}(10 \mathrm{~mol} \%)$ and $\mathrm{CuI}(10 \mathrm{~mol} \%)$ was heated under reflux in $\mathrm{Et}_{3} \mathrm{~N}(15 \mathrm{~mL})$ for $1.5-2 \mathrm{~h}$ under a nitrogen atmosphere. The resulting mixture was filtered through Celite $^{\circledR}$, washed with DCM and concentrated under vacuum. The resulting solid was purified by column chromatography.

\section{General procedure for the synthesis of 2-substituted 3-alkynyl indoles 3}

$\mathrm{NaAuCl}_{4}(2-4 \mathrm{~mol} \%)$ was added to a stirred solution of 2-alkynylaniline 2 ( $0.40 \mathrm{mmol}, 1$ equiv) in $\mathrm{iPrOH}(3 \mathrm{~mL})$ under an ambient atmosphere. The reaction was stirred at RT $\left(80^{\circ} \mathrm{C}\right.$ for $\mathbf{3 g}$ ) until full conversion (3 h). TIPS-EBX (1) (1.2-2.4 equiv) and then $\mathrm{AuCl}$ (4-8 mol \%) were added. The reaction was stirred until full conversion (4-30 h) and then concentrated 




2<smiles>[Mg][SiH2]C#Cc1c(-c2ccccc2)[nH]c2ccccc12</smiles>

3 a, $96 \%$



$3 d, 79 \%$<smiles>COc1ccc(-c2[nH]c3ccc(C#N)cc3c2C#C[SiH2]C(C)(C)C)cc1</smiles>

3 g, $79 \%$<smiles>CC(C)[Al-]C#Cc1c(-c2ccc([N+](=O)[O-])cc2)[nH]c2ccccc12</smiles>

3b, $74 \%$<smiles>Fc1ccc(-c2[nH]c3ccc(Cl)cc3c2C#C[SiH2]C(F)(F)F)cc1</smiles>

3 e, $73 \%$<smiles>CCCc1[nH]c2ccccc2c1C#C[SiH2]C(C)C</smiles>

3h, $85 \%$<smiles></smiles>

3

3c, $79 \%$<smiles>COc1ccc(-c2[nH]c3ccc(Cl)cc3c2C#C[SnH3])cc1</smiles>

3f, $56 \%, 90 \%$ pure<smiles></smiles>

$3 \mathbf{i}-\mathbf{j}$, no reaction

Scheme 6: Scope of the reaction.

under vacuum. $\mathrm{Et}_{2} \mathrm{O}(20 \mathrm{~mL})$ was added and the organic layer was washed twice with $0.1 \mathrm{M} \mathrm{NaOH}(20 \mathrm{~mL})$. The aqueous layers were combined and extracted with $\mathrm{Et}_{2} \mathrm{O}(20 \mathrm{~mL})$. The organic layers were combined, washed successively with saturated $\mathrm{NaHCO}_{3}(20 \mathrm{~mL})$ and brine $(20 \mathrm{~mL})$, dried with $\mathrm{MgSO}_{4}$ and concentrated under reduced pressure. The crude product was purified by flash chromatography.

\section{Supporting Information}

\section{Supporting Information File 1}

Experimental details and spectra of new compounds.

[http://www.beilstein-journals.org/bjoc/content/

supplementary/1860-5397-7-65-S1.pdf]

\section{Acknowledgements}

The EPFL is acknowledged for financial support and Dr. Fides Benfatti for proofreading this manuscript.

\section{References}

1. Houlihan, W. J., Ed. Indoles; The chemistry of heterocyclic compounds, Vol. 25; Wiley: New York, 1972.

2. Sundberg, R. J. Indoles; Academic Press: London, 1996.

3. Cacchi, S.; Fabrizi, G. Chem. Rev. 2005, 105, 2873-2920. doi:10.1021/cr040639b

4. Humphrey, G. R.; Kuethe, J. T. Chem. Rev. 2006, 106, 2875-2911. doi:10.1021/cr0505270

5. Tietze, L. F. Chem. Rev. 1996, 96, 115-136. doi:10.1021/cr950027e

6. Kirsch, S. F. Synthesis 2008, 3183-3204. doi:10.1055/s-0028-1083164

7. Barluenga, J.; Rodriguez, F.; Fananas, F. J. Chem.-Asian J. 2009, 4, 1036-1048. doi:10.1002/asia.200900018

8. Arcadi, A.; Cacchi, S.; Marinelli, F. Tetrahedron Lett. 1989, 30, 2581-2584. doi:10.1016/S0040-4039(01)80456-1

9. Cacchi, S. J. Organomet. Chem. 1999, 576, 42-64. doi:10.1016/S0022-328X(98)01051-1

10. Chen, Y.; Markina, N. A.; Larock, R. C. Tetrahedron 2009, 65, 8908-8915. doi:10.1016/j.tet.2009.07.075

11. Fürstner, A.; Davies, P. W. Angew. Chem., Int. Ed. 2007, 46, 3410-3449. doi:10.1002/anie.200604335

12. Hashmi, A. S. K. Chem. Rev. 2007, 107, 3180-3211. doi:10.1021/cr000436x 
13. Gorin, D. J.; Sherry, B. D.; Toste, F. D. Chem. Rev. 2008, 108, 3351-3378. doi:10.1021/cr068430g

14. Arcadi, A. Chem. Rev. 2008, 108, 3266-3325. doi:10.1021/cr068435d

15. Arcadi, A.; Bianchi, G.; Chiarini, M.; D'Anniballe, G.; Marinelli, F. Synlett 2004, 944-950. doi:10.1055/s-2004-822903

16. Alfonsi, M.; Arcadi, A.; Aschi, M.; Bianchi, G.; Marinelli, F. J. Org. Chem. 2005, 70, 2265-2273. doi:10.1021/jo047793i

17. Arcadi, A.; Bianchi, G.; Marinelli, F. Synthesis 2004, 610-618. doi:10.1055/s-2004-815947

18. Arcadi, A.; Alfonsi, M.; Bianchi, G.; D'Anniballe, G.; Marinelli, F. Adv. Synth. Catal. 2006, 348, 331-338. doi:10.1002/adsc.200505345

19. Praveen, C.; Sagayaraj, Y. W.; Perumal, P. T. Tetrahedron Lett. 2009, 50, 644-647. doi:10.1016/j.tetlet.2008.11.086

20. Praveen, C.; Karthikeyan, K.; Perumal, P. T. Tetrahedron 2009, 65, 9244-9255. doi:10.1016/j.tet.2009.09.019

21. Patil, N. T.; Singh, V.; Konala, A.; Mutyala, A. K. Tetrahedron Lett. 2010, 51, 1493-1496. doi:10.1016/j.tetlet.2010.01.036

22. Hirano, K.; Inaba, Y.; Watanabe, T.; Oishi, S.; Fujii, N.; Ohno, H. Adv. Synth. Catal. 2010, 352, 368-372. doi:10.1002/adsc.200900880

23. Nakamura, I.; Yamagishi, U.; Song, D. C.; Konta, S.; Yamamoto, Y. Angew. Chem., Int. Ed. 2007, 46, 2284-2287. doi:10.1002/anie.200604038

24. Nakamura, I.; Yamagishi, U.; Song, D.; Konta, S.; Yamamoto, Y. Chem.-Asian J. 2008, 3, 285-295. doi:10.1002/asia.200700278

25. Shimada, T.; Nakamura, I.; Yamamoto, Y. J. Am. Chem. Soc. 2004, 126, 10546-10547. doi:10.1021/ja047542r

26. Nakamura, I.; Sato, Y.; Konta, S.; Terada, M. Tetrahedron Lett. 2009, 50, 2075-2077. doi:10.1016/j.tetlet.2009.02.108

27. Li, G. T.; Huang, X. G.; Zhang, L. M. Angew. Chem., Int. Ed. 2007, 47, 346-349. doi:10.1002/anie.200702931

28. Li, X.; Wang, J. Y.; Yu, W.; Wu, L. M. Tetrahedron 2009, 65, 1140-1146. doi:10.1016/j.tet.2008.11.095

29. Arcadi, A.; Cacchi, S.; Fabrizi, G.; Marinelli, F.; Parisi, L. M. J. Org. Chem. 2005, 70, 6213-6217. doi:10.1021/jo050517z

30. Dudnik, A. S.; Gevorgyan, V. Angew. Chem., Int. Ed. 2010, 49, 2096-2098. doi:10.1002/anie.200906755

31. Messaoudi, S.; Brion, J. D.; Alami, M. Eur. J. Org. Chem. 2010, 6495-6516. doi:10.1002/ejoc.201000928

32. Gu, Y. H.; Wang, X. M. Tetrahedron Lett. 2009, 50, 763-766. doi:10.1016/j.tetlet.2008.11.097

33. de Haro, T.; Nevado, C. J. Am. Chem. Soc. 2010, 132, 1512-1513. doi:10.1021/ja909726h

34. Yang, L.; Zhao, L. A.; Li, C. J. Chem. Commun. 2010, 46, 4184-4186. doi:10.1039/C0CC00014K

35. Brand, J. P.; Charpentier, J.; Waser, J. Angew. Chem., Int. Ed. 2009, 48, 9346-9349. doi:10.1002/anie.200905419

36. Zhdankin, V. V.; Kuehl, C. J.; Krasutsky, A. P.; Bolz, J. T.; Simonsen, A. J. J. Org. Chem. 1996, 61, 6547. doi:10.1021/jo960927a

37. Nicolai, S.; Erard, S.; Fernandez Gonzalez, D.; Waser, J. Org. Lett. 2010, 12, 384-387. doi:10.1021/ol9027286

38. Fernandez Gonzalez, D.; Brand, J. P.; Waser, J. Chem.-Eur. J. 2010, 16, 9457-9461. doi:10.1002/chem.201001539

39. Brand, J. P.; Waser, J. Angew. Chem., Int. Ed. 2010, 49, 7304-7307. doi:10.1002/anie.201003179

40. Brand, J. P.; Fernandez Gonzalez, D.; Nicolai, S.; Waser, J. Chem. Commun. 2011, 47, 102-115. doi:10.1039/C0CC02265A

41. Yin, Y.; Ma, W. Y.; Chai, Z.; Zhao, G. J. Org. Chem. 2007, 72, 5731-5736. doi:10.1021/jo070681h

42. Swamy, N. K.; Yazici, A.; Pyne, S. G. J. Org. Chem. 2010, 75, 3412-3419. doi:10.1021/jo1005119

\section{License and Terms}

This is an Open Access article under the terms of the Creative Commons Attribution License

(http://creativecommons.org/licenses/by/2.0), which permits unrestricted use, distribution, and reproduction in any medium, provided the original work is properly cited.

The license is subject to the Beilstein Journal of Organic Chemistry terms and conditions:

(http://www.beilstein-journals.org/bjoc)

The definitive version of this article is the electronic one which can be found at: doi:10.3762/bjoc. 7.65 